Article

\title{
Experimental Investigation and Discussion on the Mechanical Endurance Limit of Nafion Membrane Used in Proton Exchange Membrane Fuel Cell ${ }^{\dagger}$
}

\section{Yang Xiao and Chongdu Cho *}

Department of Mechanical Engineering, Inha University, 253 Yonghyun-dong, Nam-Gu, Incheon 402-751, Korea; E-Mail: yangxiao@inha.edu

$\dagger$ This paper is the improvement of the proceeding of 1st Int. e-Conf. on Energies: Xiao, Y.; Wendling, L.; Cho, C. Experimental Investigation on the Mechanical Endurance Limit of Nafion membrane used in Proton Exchange Membrane Fuel Cell. In Proceedings of the 1st Int. e-Conf. on Energies, 14-31 March 2014; Sciforum Electronic Conference Series, Vol. 1, 2013, d005; doi:10.3390/ece-1-d005.

* Author to whom correspondence should be addressed; E-Mail: cdcho@inha.ac.kr; Tel.: +82-32-860-7321; Fax: +82-32-872-7322.

External Editor: Enrico Sciubba

Received: 28 July 2014; in revised form: 16 September 2014 / Accepted: 28 September 2014 / Published: 9 October 2014

Abstract: As a solution of high efficiency and clean energy, fuel cell technologies, especially proton exchange membrane fuel cell (PEMFC), have caught extensive attention. However, after decades of development, the performances of PEMFCs are far from achieving the target from the Department of Energy (DOE). Thus, further understanding of the degradation mechanism is needed to overcome this obstacle. Due to the importance of proton exchange membrane in a PEMFC, the degradation of the membrane, such as hygrothermal aging effect on its properties, are particularly necessary. In this work, a thick membrane (Nafion N117), which is always used as an ionic polymer for the PEMFCs, has been analyzed. Experimental investigation is performed for understanding the mechanical endurance of the bare membranes under different loading conditions. Tensile tests are conducted to compare the mechanical property evolution of two kinds of bare-membrane specimens including the dog-bone and the deeply double edge notched (DDEN) types. Both dog-bone and DDEN specimens were subjected to a series of degradation tests with 
different cycling times and wide humidity ranges. The tensile tests are repeated for both kinds of specimens to assess the strain-stress relations. Furthermore, Fourier transform infrared spectroscopy (FT-IR), X-ray diffraction (XRD) and Scanning electron microscope (SEM) observation and water absorption measurement were conducted to speculate the cause of this variation. The initial cracks along with the increasing of bound water content were speculated as the primary cause.

Keywords: proton exchange membrane fuel cell (PEMFC); Nafion; fracture test; hygrothermal aging; mechanical endurance

\section{Introduction}

Proton exchange membrane fuel cell (PEMFC) has very high performance in a wide working range with good dynamic characteristics and it works at a low temperature. PEMFC also has showed high efficiency of electrical conversion and the total efficiency can be even higher by making full use of the heat generated during the operation. It generates electricity without any emissions and most of the materials employed can be reused or recycled [1]. It was reported in 2010 that PEMFC can reach $\sim 60 \%$ electricity conversion efficiency and $80 \%$ energy co-generation (electrical and thermal) efficiency with more than $90 \%$ reduction of carbon and pollution emissions.

Nevertheless, before that, the low durability of PEMFC is the primary problems that need to be solved. The DOE (Department of Energy) target for the lifetime of fuel cell is more than $5000 \mathrm{~h}$ for transportation applications by 2015 and $40,000 \mathrm{~h}$ for stationary applications by 2011 . According to this target, now the performance of PEMFC is far from achieving the target [2]. Thus, further understanding of the degradation mechanism and development of durability analysis methods are needed to overcome this obstacle.

Within an operating circle of the PEMFC, the diffusion of reactants, the oxidation and reduction of reactants and the conduction of protons, they all take place in the membrane electrode assembly (MEA) where the temperature, humidity and external compressive load have very high variation. The MEA bears the temperature over $80{ }^{\circ} \mathrm{C}$ and the humidity from Relative Humidity (RH) $30 \%$ to RH 90\% [3]. During the operating very complex phenomenon are involved in the thin MEA, including heat transfer, multiphase flows, electrochemical reactions, charge transport, and mechanical interactions. That is why premature failures in MEA are always observed in forms of throughout crack and delamination [4]. If it is observed in single layer, the failure turns to be cracks, tears, punctures and pinholes though the membrane and cracks and flaking of catalyst layer (CL) (also known as the electrode) [5]. The mechanical causes of these premature failures include orientation of material on CL (the electrode) [6], the creep of membrane material and damage accumulation. During multiple cycles of operation, with the change of temperature and humidity, the swelling of the membrane is the primary drive force and the main factor, which affects the stress distribution through MEA [7]. The alternation between wet-up and dry-out can cause significant stresses in membrane [8]. Additionally, freeze and thaw cycles also induce physical damages to the MEA [9]. 
In literatures, most of the degradation researches focus on the electrical/chemical performance in terms of proton transport ability, cell voltage and current density [10,11]. In mechanical field, the nonlinear viscoelastic-viscoplastic constitutive models of the membrane are widely discussed, especially on the rate, temperature, and hydration dependence $[12,13]$. The experimental investigations on the mechanical responses of ionomer membranes under different conditions are conducted as well $[7,14]$. However, there are few papers discuss the change of mechanical properties after the membranes sustained the working cycles. Although it is important in accurate modeling, as well as the potential failure analysis.

To fill this blank, the mechanical degradation data of the membrane, Nafion, which is the most widely used ionic polymer of PEMFCs, should be obtained as a database in order to make a contribution to PEMFC degradation modeling and simulation. In this paper, two kinds of tests were conducted including the dog-bone tensile test and deeply double edge notched test (DDENT). The mechanical properties, in terms of Young's modulus, yielding strain, specific essential work of fracture and so on, were obtained [15]. In addition, the difference of mechanical properties between untreated and aged specimens was analyzed. Furthermore, Fourier transform infrared spectroscopy (FT-IR), $\mathrm{X}$-ray diffraction (XRD) observation and water absorption measurement were conducted to speculate the cause of this variation.

\section{Experimental Section}

\subsection{Materials}

Non-reinforced films based on chemically stabilized perfluorosulfonate acid (PFSA) and polytetrafluoro-ethylene (PTFE) copolymer in the acid $\left(\mathrm{H}^{+}\right)$form, which was obtained from Dupont Company with the commercial name Nafion ${ }^{\circledR}$ N117 (DuPont Korea, Inc., Seoul, Korea).

\subsection{Specimen}

There were two kinds of specimens, the dog-bone ones and the DDEN ones. The dimensions of both specimens are shown in Figure 1a, where $L$ equal to $10 \mathrm{~mm}$. All the specimens are cut in shape (including the deep notches of DDENT specimens) before cycling.

Figure 1. The dimensions of (a) dog-bone specimen [16] and (b) deeply double edge notched test (DDENT) specimen; (c) The curves of Humidity and Temperature cycling with one period.

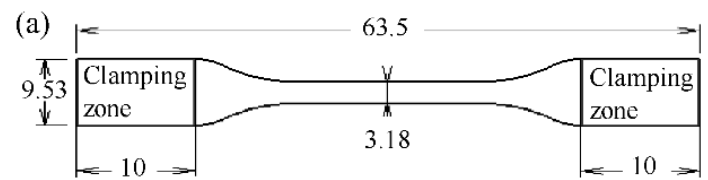

(b)

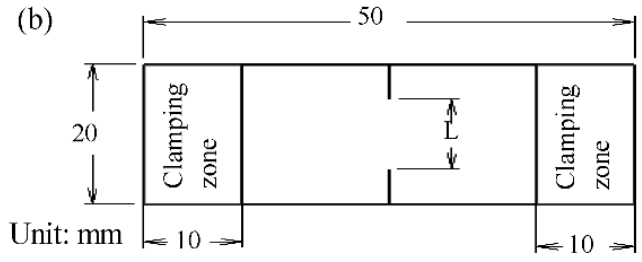

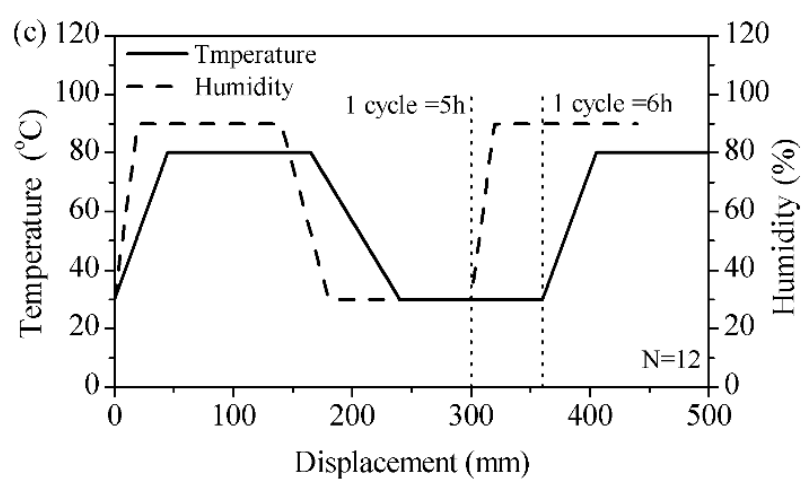


Both kinds of specimens are divided into three groups, untreated, humidity cycling aged and temperature cycling aged. Both humidity and temperature aged specimens were maintained with no constraint (free to expand) in the temperature and humidity incubator for 12 cycles to analog the real Fuel cell working condition. The humidity and temperature change is shown in Figure 1c. It should be noted that the temperature was maintained constant as room temperature $\left(25{ }^{\circ} \mathrm{C}\right)$ during humidity cycles and the humidity was also maintained constant at $30 \%$ during temperature cycles.

\subsection{Mechanical Properties}

Mechanical properties of Nafion N117 membrane were measured by tensile tester (BS-205, C\&FO, Siheung, Korea) with a load sensitivity of $0.1 \mathrm{~N}$. For the tensile test, the strain rate is the most important factor, which should be carefully determined. Normally, if the strain rate is lower than $0.001 \mathrm{~s}^{-1}$, the tests would be considered as quasi-static tests that are not suitable for the purpose of our study, and according to the literatures discussing the mechanical response of Nafion membranes $[13,17,18]$, we chose two test strain rates, $0.01 \mathrm{~s}^{-1}$ and $0.001 \mathrm{~s}^{-1}$. Moreover, the tensile tests were conducted at room temperature $\left(25^{\circ} \mathrm{C}\right)$.

To avoid the influence of temperature and humidity residual, all the specimens, untreated and aged for 12 cycles, were maintained in room conditions $\left(25^{\circ} \mathrm{C}\right.$ and $\left.\mathrm{RH} 30 \%\right)$ for $24 \mathrm{~h}$ before testing.

\subsection{Observation and Measurement}

It is well known that the changing of mechanical properties must due to the variation of the material micro-structure. To verify what happened in the micro-structure of the specimens, FT-IR, XRD observation and water absorption measurement were conducted.

The room temperature Fourier transform infrared spectrum of the specimens (both untreated and aged) was measured in the region 400-4000 $\mathrm{nm}$ region using a BRUKER VERTEX 80V FT-IR (Bruker Optics Inc., Billerica, MA, USA) spectrometer equipped with $\mathrm{KBr}$ powder were used in the spectral measurements.

XRD data were obtained at the Laboratory of X-ray crystallography of untreated and aged Nafion specimens, using a Philips X'Pert MPO PRO diffractometer (PANalytical B.V., Almelo, The Netherlands) equipped with graphite monochromator and rotating anode tube, operating with ceramic $\mathrm{Cu}$ target, $60 \mathrm{kV}$ and $60 \mathrm{~mA}$. Powder diffraction patterns were obtained in steps canning mode, $2 \theta=10^{\circ}-90^{\circ}$, step of $0.02^{\circ}$ and $5 \mathrm{~s} / \mathrm{step}$.

Porosity measurement was conducted at room temperature using deionized water as the saturation fluid. In each group, untreated, humidity cycling aged and temperature cycling aged, there are 10 specimens. All the specimens were cut into squares with the edge length of $9.53 \mathrm{~mm}$. In addition, they were weighted by a METTLER TOLEDO AT201 precision scale (Mettler-Toledo AG, Greifensee, Switzerland) ( $\max 205 \mathrm{~g}$, accuracy $0.01 \mathrm{mg}$ ). After the weight data was recorded, the specimens were immersed into deionized water for $30 \mathrm{~min}$ until they were fully saturated. With the water on the surface wiped off, the saturation weights were measured with the same precision scale, respectively. 
The specimens treated differently were coated by a Turbo Pumped Sputter Coater (Q150T) (Quorum Technologies Ltd., West Sussex, UK) with Pt for $180 \mathrm{~s}$. The morphology investigation was completed using a high-resolution scanning electron microscope (HR-SEM, SU 8010, Hitachi High-Technologies Europe GmbH, Krefeld, Germany).

\section{Results and Discussion}

\subsection{Dog-Bone Tensile Test}

The response of a typical polymer is shown as Figure 2a.

As we know, the response of Nafion membrane includes both intermolecular resistance and network stress [18]. Moreover, the total response can be divided into two zones termed as pre-yield and post-yield zones by the potential barrier. After the post yielding, the total response is nearly linear, so we cropped the curves with the true strain range from 0 to 0.18 in order to have a clearer scope of yielding behavior. The curves of true stress-true strain of Nafion N117 dog-bone specimens are shown in Figure $2 b$.

Figure 2. (a) True stress-true strain curve of a typical polymer and different zones;

(b) The true stress-true strain curves of N117 dog-bone tensile test under different strain rates $\left(0.01 \mathrm{~s}^{-1}\right.$ and $\left.0.001 \mathrm{~s}^{-1}\right)$ and different cycling treatments.
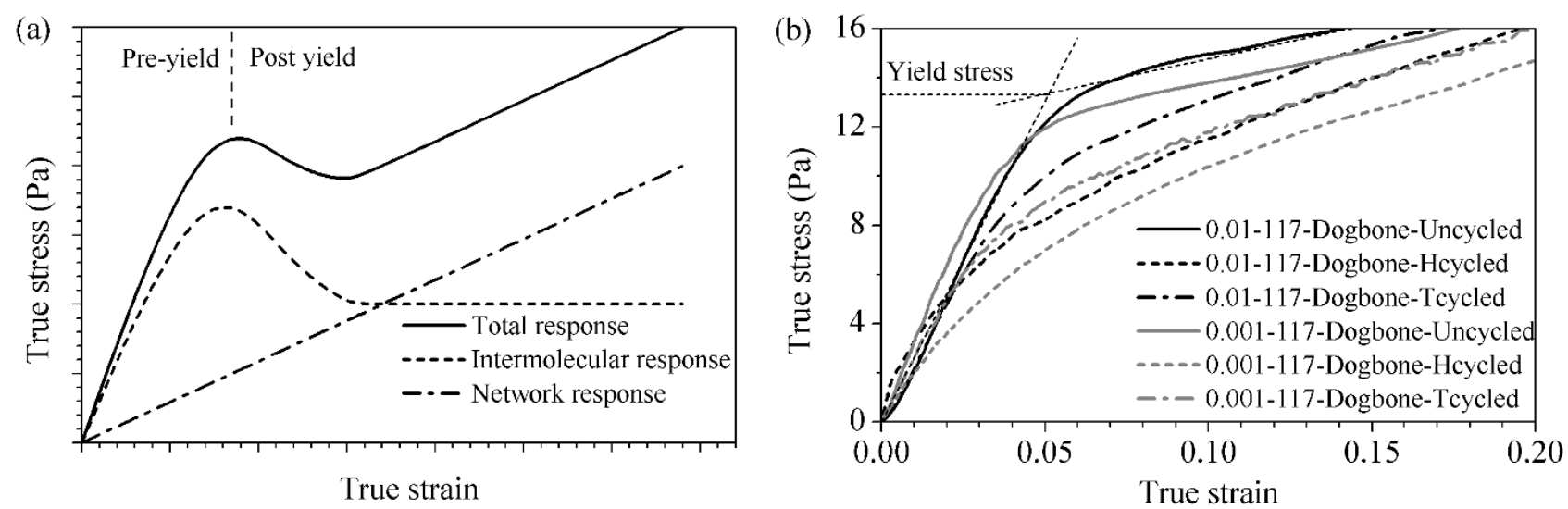

The stress at the intersection of linear fits to the pre-yield zone slope and the immediate post-yield zone slope is named the yield stress. The yield stress usually referred that can be affected by both deformation rate and temperature. In Figure $2 b$, we can tell it is also affected by aging treatment.

Besides, the yielding behaviors are also changed largely after the aging treatment applied. In the total response the network stress is linear [19], that is to say the stress produced by the network is in proportion to the true strain, according to Figure $2 b$ the curves are nearly parallel to each other when strain is larger than 0.14 , that means the network response was hardly affected by the aging treatments. However, the potential barrier had decreased after cycling, so it can be asserted that the aging treatments affect the interaction of molecular chains in membrane structure.

The yielding stresses abstracted form Figure $2 b$ are shown as in Figure 3. 
Figure 3. The (a) yielding stress and (b) Young's modulus of N117 dog-bone tensile test under different strain rates $\left(0.01 \mathrm{~s}^{-1}\right.$ and $\left.0.001 \mathrm{~s}^{-1}\right)$ and different cycling treatments.
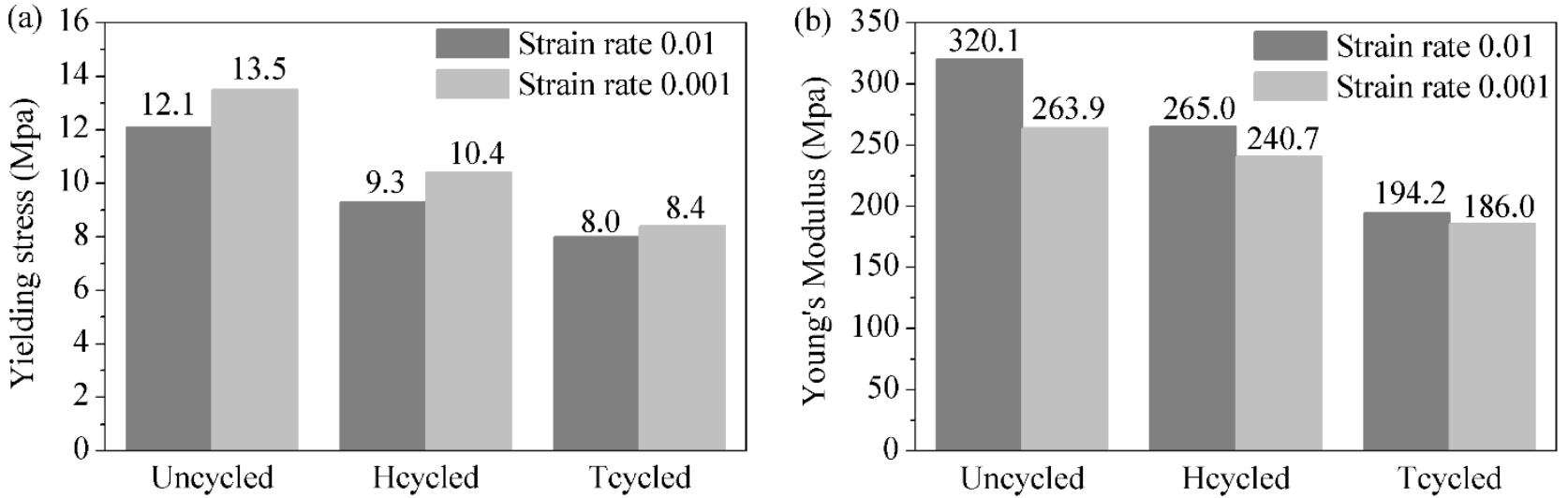

\subsection{Deeply Double Edge Notched Test}

Because of the fracture generation, the section area of specimen is changing with time. It is impossible to get the true stress, so the results of DDENT should be presented by force-displacement curves.

As shown in Figure 4a, all the factors, such as tensile speed, humidity aging and temperature aging, have an obvious influence on the total work of fracture (the area bounded by the force-displacement and $\mathrm{x}$ axle). With a higher strain rate, the maximum force to start facture is larger, but this kind of influence is not obvious in the aged specimens.

Figure 4. (a) The force-displacement curves of N117 DDENT with $L=10 \mathrm{~mm}$ under different strain rates $\left(0.01 \mathrm{~s}^{-1}\right.$ and $\left.0.001 \mathrm{~s}^{-1}\right)$ and different cycling treatments; (b) The work of fracture of N117 DDENT with $L=10 \mathrm{~mm}$ under different strain rates $\left(0.01 \mathrm{~s}^{-1}\right.$ and $0.001 \mathrm{~s}^{-1}$ ) and different cycling treatments.
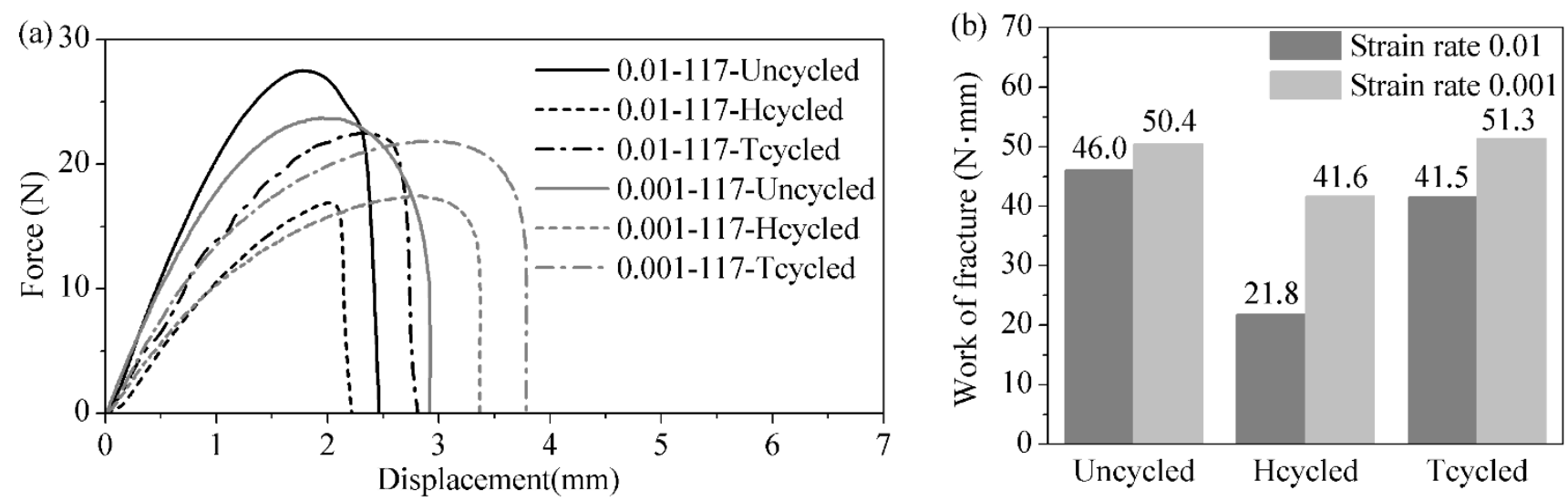

Both humidity and temperature aged specimens showed a resistance with larger extension when the loads were applied at a lower strain rate.

As shown in Figure 4b, the work of facture calculated from the force-displacement curves showed that after the temperature aging the energy needed to break the sample did not change much. However, after the humidity aging, the work needed decreased largely and this effect enlarged by higher strain rate. 


\subsection{Observation and Measurement}

As we speculated from the results of tensile tests, the network response was hardly affected by the aging treatments. However, the aging treatment affected the interaction of molecular chains in membrane structure. The variation of the molecular interactions may include fragmentation of macromolecule chains, entanglement situation changing [20], bound water content, etc. To verify each of these factors, FT-IR, XRD, SEM observation and water absorption measurement were conducted.

Here, FI-IR is a technique that is used to obtain an infrared spectrum of absorption of nafion membranes. The FTIR spectrometer simultaneously collects spectral data in a wide spectral range. This confers a significant advantage over a dispersive spectrometer that measures intensity over a narrow range of wavelengths at a time. By analyzing the shape of spectra and peaks, we can infer the specific function groups. If there is any fragmentation of macromolecule chains, the number and position of the characteristic peaks should be changed. However, as shown in Figure 5a, only a negligible difference can be observed in the high wave number rage. The characteristic peaks for all groups of specimens, untreated, humidity cycling aged and temperature cycling aged, are nearly the same in both the position and height. That is to say, there are few chains broken, so the fragmentation of chains is not the main cause lead to the mechanical degradation.

Figure 5. (a) Fourier transform infrared spectroscopy (FT-IR) spectra of Nafion membrane specimens, untreated, humidity cycling aged and temperature cycling aged; (b) X-ray diffraction (XRD) spectra of Nafion membrane specimens, untreated, humidity cycling aged and temperature cycling aged.

(a)

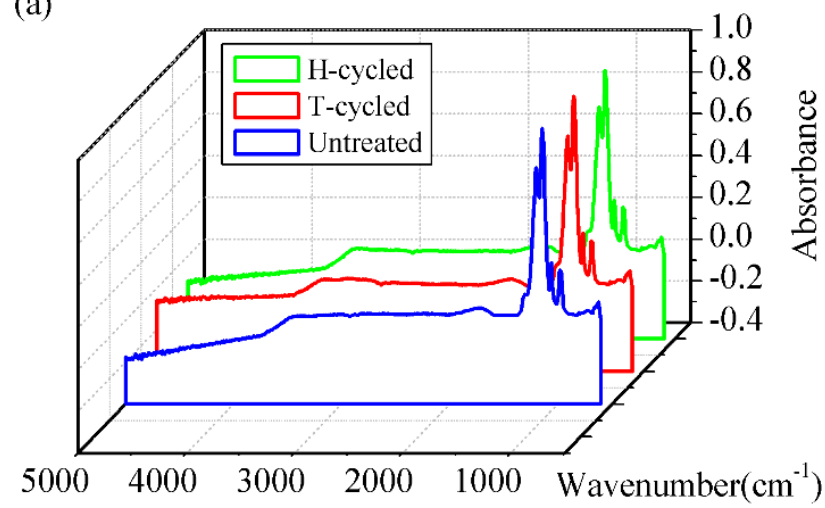

(b)

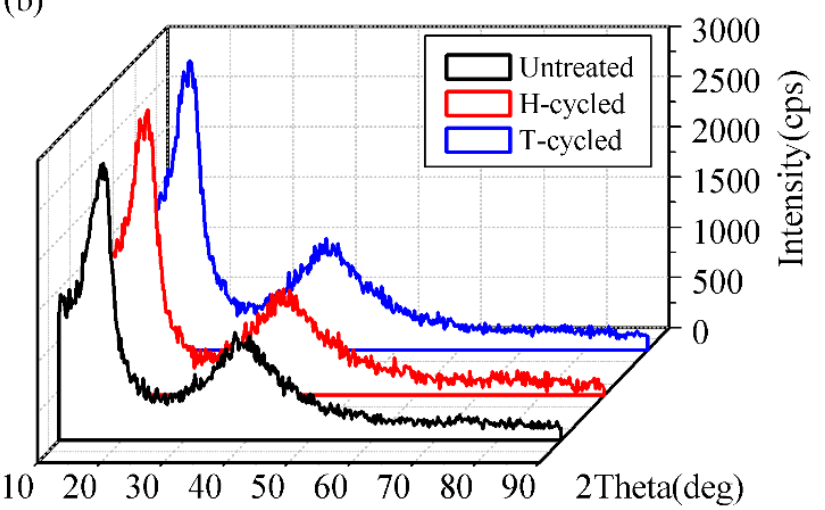

XRD is a tool used here for identifying the atomic and molecular structure, in which the crystalline atoms cause a beam of incident X-rays to diffract into many specific directions. By measuring the average spacing between layers or rows of atoms, the entanglement situation can be analyzed [21]. If the entanglement situation changed, that means the degree of crystallinity has been changed. It is possibly manifested in both and amount of crystalline grains. The curves are shown in Figure $5 \mathrm{~b}$ as the spectrums of the untreated, humidity cycling aged and temperature cycling aged specimens. There is no change of the characteristic peaks before and after treatment, so we can ensure that the entanglement situation has not been changed by the aging treatments.

The averaged dry weights and saturate weights are listed in Table 1. The water absorption percentages are calculated as the Equation (1): 


$$
\phi=\frac{m_{\mathrm{sat}}-m_{\mathrm{dry}}}{m_{\mathrm{dry}}} \times 100 \%
$$

where $m_{\text {sat }}$ is the averaged saturate weight, $m_{\text {dry }}$ is the averaged dry weight, $\phi$ is the mass percentage of the absorbed water.

From Table 1, we can obviously see that the water absorptions of the treated specimens, no matter temperature cycles aged or humidity cycles aged ones, have decreased largely. In order to make it more clear, the data of Table 1 is expressed by a column chart in Figure 6.

Table 1. Averaged weights of the specimens experienced different treatments and calculated water absorption percentages.

\begin{tabular}{cccc}
\hline Treatment & Dry Weight $(\mathbf{g})$ & Saturate Weight $\mathbf{( g )}$ & Water Absorption (\%) \\
\hline Untreated & 0.03191 & 0.03631 & 13.79 \\
T-cycled & 0.03301 & 0.03627 & 9.88 \\
H-cycled & 0.03315 & 0.03625 & 9.36 \\
\hline
\end{tabular}

As shown in Figure 6, it is obvious to see the averaged saturate weight for all the specimens are nearly the same, however, the dry weight of the specimens are different a with different treatment. And due to these differences the water absorption percentages turned to be different.

Figure 6. Averaged weights of the specimens after different treatments and the water absorption percentages.

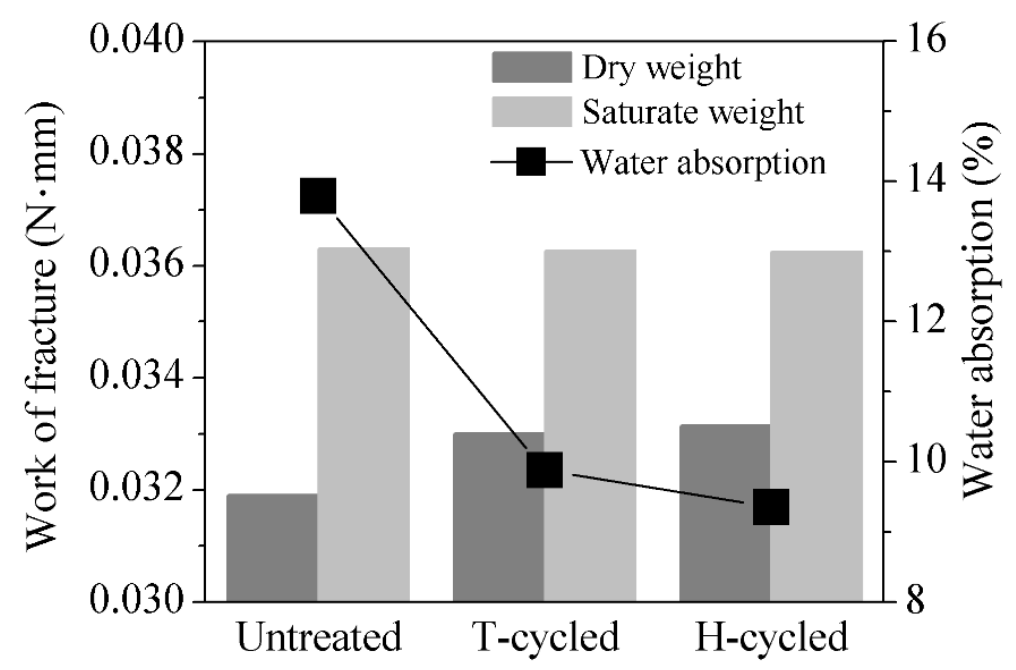

During the treatment procedure, all the specimens were maintained under the same condition for $24 \mathrm{~h}$, which is much more than enough time to get rid of the free water content. However, Figure 6 shows that the dry weight of aged specimens was higher than untreated ones, and this difference disappeared after saturated water. Thus, we can believe that after the aging treatment, about $4 \%$ mass percentage of water was turned into bound water and cannot be removed by evaporation under room temperature.

SEM images in Figure 7 shows a more direct view of the morphology of the specimens, It can be observed that most of the nafion agglomerates shown in Figure $7 \mathrm{~b}, \mathrm{c}$ are bigger than what is shown in Figure 7a. Therefore, we believe that the increase of agglomerate size is due to the existence of the bound water. What is more, initial cracks occurred around the big agglomerates (marked by the arrows 
in the figure). Moreover, it can be another explanation of the vanishment of potential barrier, as well as the decreasing of the material strength.

Figure 7. Comparison of the surface morphologies of (a) untreated; (b) humidity aged and (c) temperature aged Nafion membrane specimens.

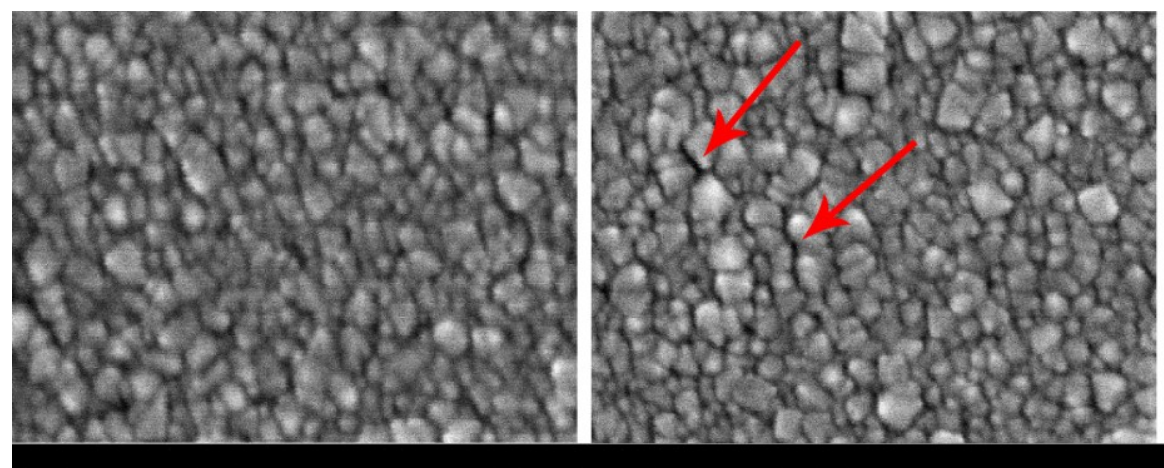

Inha 15.0kV 8.0mm x150k SE(U) 9/16/2014

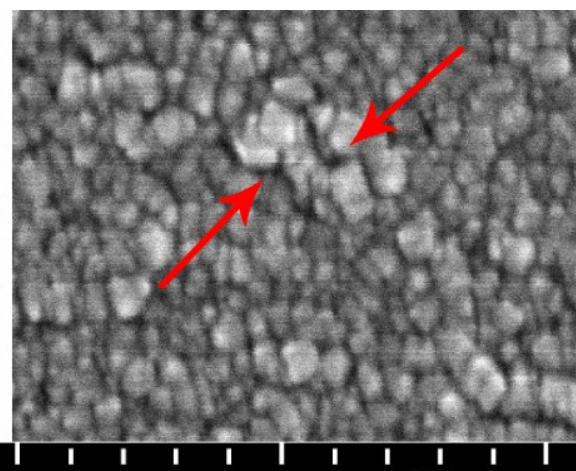

$300 \mathrm{~nm}$

Above all, it can be speculated that because of the increasing of bound water content the agglomerate size of Nafion ionomer enlarged, and it leads to the occurrence of initial micro cracks. Because of this variation, the phenomenon had been observed as the potential barrier has disappeared, then it leads to the variation of yielding behavior of Nafion membrane.

\section{Conclusions}

This work can be summarized with the following conclusions.

The strength of Nafion membranes as well as the work of fracture was affected largely by the aging treatment. Moreover, the humidity aging has the greater impact.

The values of the mechanical properties are obtained to fill the blank of aged nafion properties, which is necessary in the PEMFC degradation simulation.

The molecular chains of Nafion do not change after the treatments, fragmentation of macromolecule chains or entanglement situation changing barely happen. Nevertheless, the bound water content increased after aging treatments. Different from the free water, bound water cannot be removed by evaporation under room temperature.

The agglomerate size of Nafion ionomer increased due the increase of bound water content, along with this are the generation of initial cracks.

We can speculate that the initial cracks along with the increasing of Nafion bound water content lead to the changing of the yielding behavior, which concretely presents as the disappearance of potential barrier during tensile test.

\section{Acknowledgments}

This work was supported by the National Research Foundation of Korea Grant funded by the Korea Government (MEST; No. 2011-0015728) and Inha University. 


\section{Author Contributions}

Yang Xiao prepared the manuscript and undertook the majority of experiments as well as the data analysis in the paper under the guidance of Chongdu Cho. And Chongdu Cho reviewed the manuscript.

\section{Conflicts of Interest}

The authors declare no conflict of interest.

\section{References}

1. Barbir, F.; Gomez, T. Efficiency and economics of proton exchange membrane (PEM) fuel cells. Int. J. Hydrog. Energy 1996, 21, 891-901.

2. Wang, Y.; Chen, K.S.; Mishler, J.; Cho, S.C.; Adroher, X.C. A review of polymer electrolyte membrane fuel cells: Technology, applications, and needs on fundamental research. Appl. Energy 2011, 88, 981-1007.

3. Peker, M.F.; Cora, O.N.; Koc, M. Investigations on the variation of corrosion and contact resistance characteristics of metallic bipolar plates manufactured under long-run conditions. Int. $J$. Hydrog. Energy 2011, 36, 15427-15436.

4. Xie, J.; Wood, D.L.; Wayne, D.M.; Zawodzinski, T.A.; Atanassov, P.; Borup, R.L. Durability of PEFCs at high humidity conditions. J. Electrochem. Soc. 2005, 152, A104-A113.

5. Zhang, S.S.; Yuan, X.Z.; Wang, H.J.; Merida, W.; Zhu, H.; Shen, J.; Wu, S.H.; Zhang, J.J. A review of accelerated stress tests of MEA durability in PEM fuel cells. Int. J. Hydrog. Energy 2009, 34, $388-404$.

6. Kundu, S.; Fowler, M.W.; Simon, L.C.; Grot, S. Morphological features (defects) in fuel cell membrane electrode assemblies. J. Power Sources 2006, 157, 650-656.

7. Kusoglu, A.; Karlsson, A.M.; Santare, M.H.; Cleghorn, S.; Johnson, W.B. Mechanical behavior of fuel cell membranes under humidity cycles and effect of swelling anisotropy on the fatigue stresses. J. Power Sources 2007, 170, 345-358.

8. Solasi, R.; Zou, Y.; Huang, X.; Reifsnider, K.; Condit, D. On mechanical behavior and in-plane modeling of constrained PEM fuel cell membranes subjected to hydration and temperature cycles. J. Power Sources 2007, 167, 366-377.

9. Kim, S.; Ahn, B.K.; Mench, M.M. Physical degradation of membrane electrode assemblies undergoing freeze/thaw cycling: Diffusion media effects. J. Power Sources 2008, 179, 140-146.

10. Sahu, A.K.; Pitchumani, S.; Sridhar, P.; Shukla, A.K. Nafion and modified-Nafion membranes for polymer electrolyte fuel cells: An overview. Bull. Mater. Sci. 2009, 32, 285-294.

11. Fernandes, A.C.; Ticianelli, E.A. A performance and degradation study of Nafion 212 membrane for proton exchange membrane fuel cells. J. Power Sources 2009, 193, 547-554.

12. Yoon, W.; Huang, X. A nonlinear viscoelastic-viscoplastic constitutive model for ionomer membranes in polymer electrolyte membrane fuel cells. J. Power Sources 2011, 196, 3933-3941.

13. Silberstein, M.N.; Boyce, M.C. Constitutive modeling of the rate, temperature, and hydration dependent deformation response of Nafion to monotonic and cyclic loading. J. Power Sources 2010, 195, 5692-5706. 
14. Kusoglu, A.; Karlsson, A.M.; Santare, M.H.; Cleghorn, S.; Johnson, W.B. Mechanical response of fuel cell membranes subjected to a hygro-thermal cycle. J. Power Sources 2006, 161, 987-996.

15. Xiao, Y.; Wendling, L.; Cho, C. Experimental investigation on the mechanical endurance limit of nafion membrane used in proton exchange membrane fuel cell. In Proceedings of the 1st International e-Conference on Energies, Basel, Switzerland, 14-31 March 2014; Volume 1, p. d005.

16. American Society for Testing and Materials (ASTM). Tensile Properties of Plastics; ASTM D638-10; ASTM: West Conshohocken, PA, USA, 2010; p. D638.

17. Silberstein, M.N.; Boyce, M.C. Hygro-thermal mechanical behavior of Nafion during constrained swelling. J. Power Sources 2011, 196, 3452-3460.

18. Arruda, E.M.; Boyce, M.C.; Jayachandran, R. Effects of strain-rate, temperature and thermomechanical coupling on the finite strain deformation of glassy-polymers. Mech. Mater. 1995, 19, 193-212.

19. Mulliken, A.D.; Boyce, M.C. Mechanics of the rate-dependent elastic-plastic deformation of glassy polymers from low to high strain rates. Int. J. Solids Struct. 2006, 43, 1331-1356.

20. Riku, I.; Mimura, K. Computational characterization on mechanical behavior of polymer electrolyte membrane based on nonaffine molecular chain network model. Int. J. Mech. Sci. 2010, 52, 287-294.

21. Ludvigsson, M.; Lindgren, J.; Tegenfeldt, J. Crystallinity in cast Nafion. J. Electrochem. Soc. 2000, 147, 1303-1305.

(C) 2014 by the authors; licensee MDPI, Basel, Switzerland. This article is an open access article distributed under the terms and conditions of the Creative Commons Attribution license (http://creativecommons.org/licenses/by/4.0/). 